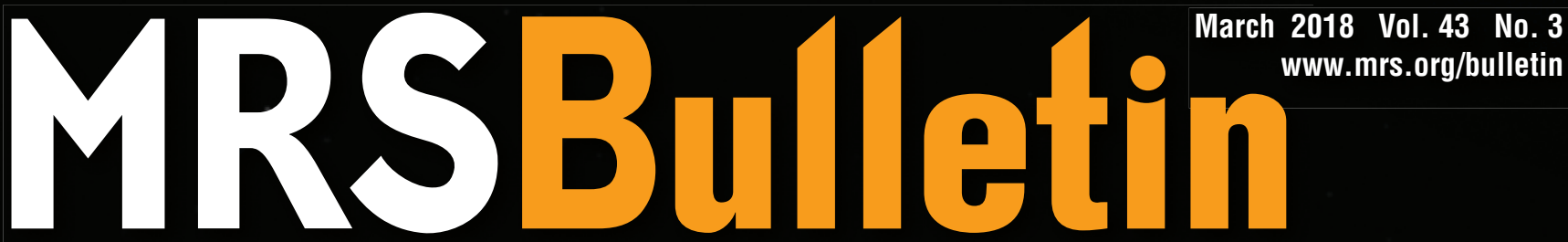

\begin{tabular}{l|l|l|l}
$M$ & $R$ & $S$ & $\begin{array}{l}\text { MATERIALS RESEARCH SOCIETY } \\
\text { Advancing materials. Improving the quality of life. }\end{array}$
\end{tabular}

\title{
Materials for energy harvesting
}

ALSO IN THIS ISSUE Glimpses of 60 years of research in materials chemistry

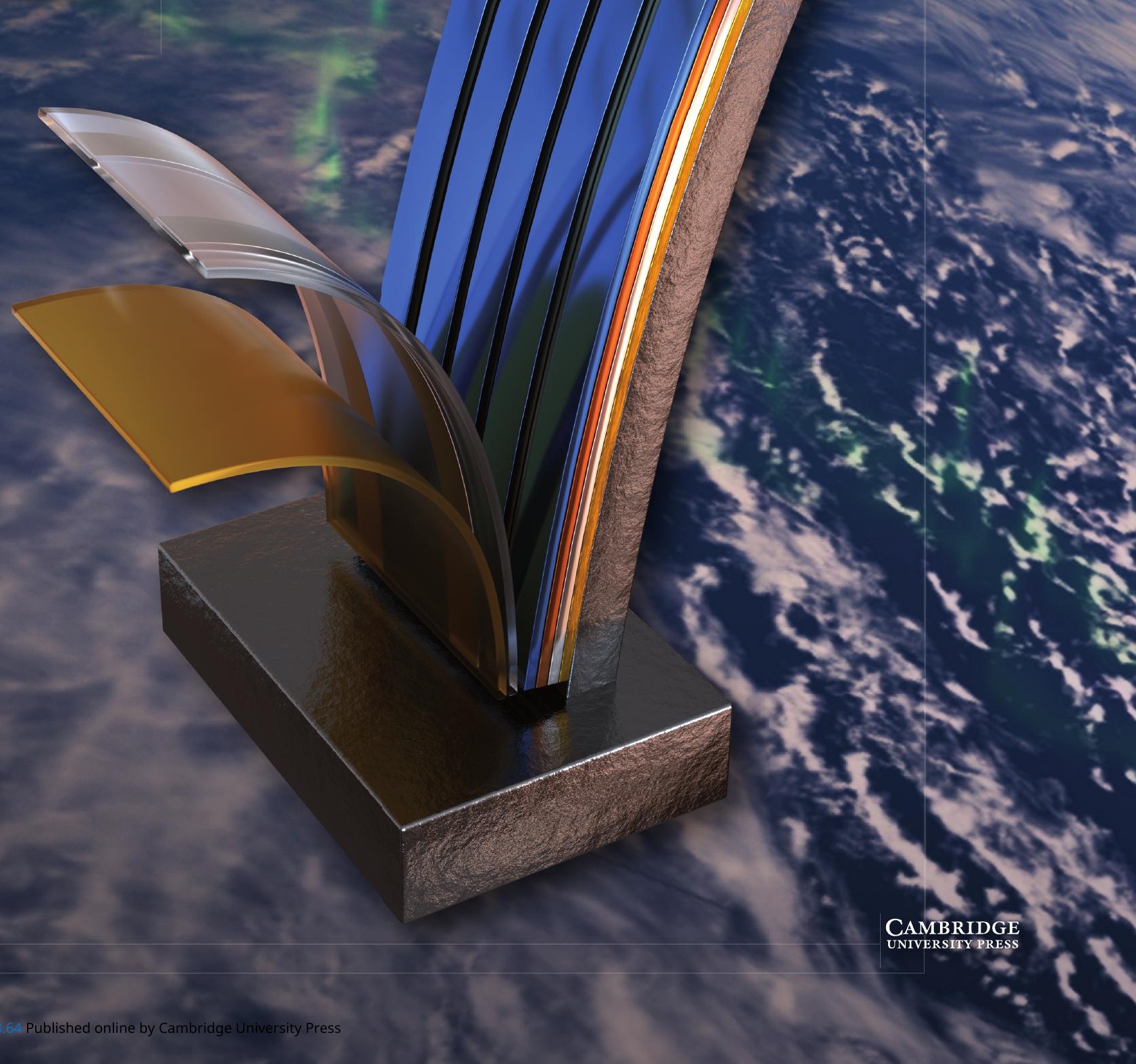




\section{CUSTOMIZED PRODUCTION ION IMPLANTERS}

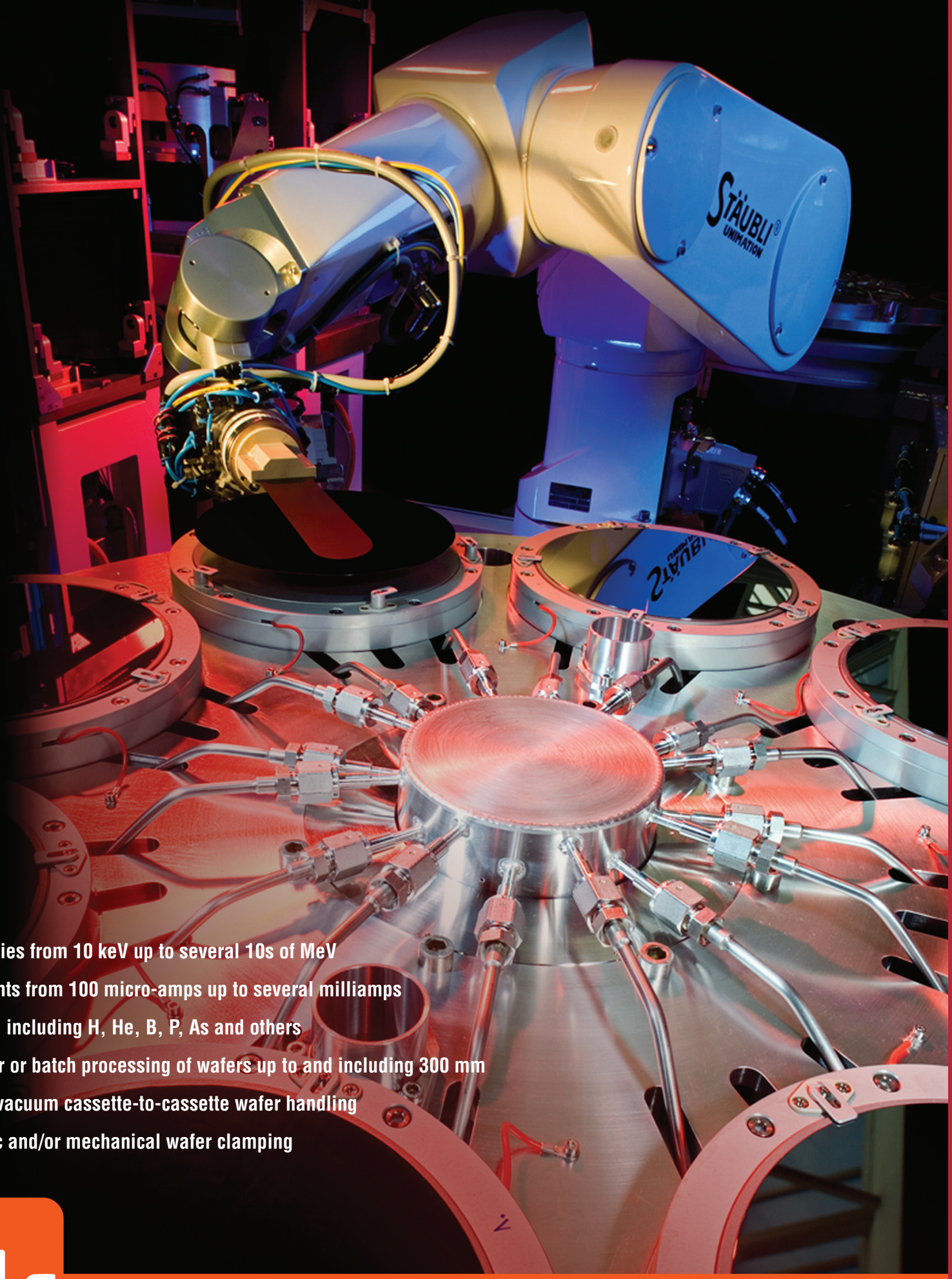

Beam energies from $10 \mathrm{keV}$ up to several $10 \mathrm{~s}$ of MeV

Beam currents from 100 micro-amps up to several milliamps

Ion species, including $\mathrm{H}, \mathrm{He}, \mathrm{B}, \mathrm{P}$, As and others

Single wafer or batch processing of wafers up to and including $300 \mathrm{~mm}$

In-air or in-vacuum cassette-to-cassette wafer handling

- Electrostatic and/or mechanical wafer clamping 


\section{Sigma-Aldrich.}




\section{MRSBulletin}

March 2018 Volume 43 Number 3 ISSN: 0883-7694 CODEN: MRSBEA
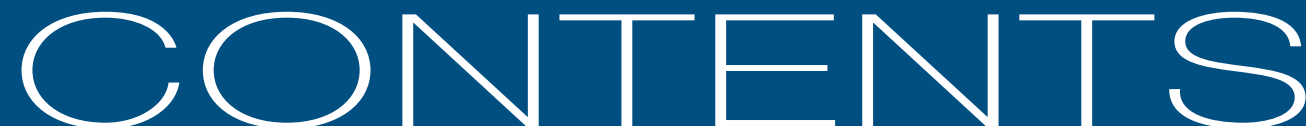

\section{MATERIALS FOR ENERGY HARVESTING}

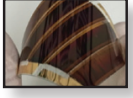

176 Materials for energy harvesting:

At the forefront of a new wave

Takao Mori and Shashank Priya, Guest Editors

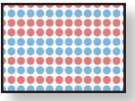

181 Nano-microstructural control of phonon engineering for thermoelectric energy harvesting

Zihang Liu, Jun Mao, Te-Huan Liu, Gang Chen, and Zhifeng Ren

187 Quantum materials for thermoelectricity Johannes Gooth, Gabi Schierning, Claudia Felser, and Kornelius Nielsch

193 Wearable and flexible thermoelectrics for energy harvesting

Ruoming Tian, Chunlei Wan, Naoyuki Hayashi, Toshiaki Aoai, and Kunihito Koumoto

199 Dual-stimulus magnetoelectric energy harvesting

Zhaoqiang Chu, Venkateswarlu Annapureddy, MohammadJavad PourhosseiniAsl, Haribabu Palneedi, Jungho Ryu, and Shuxiang Dong

206 Materials and approaches for on-body energy harvesting

Shad Roundy and Susan Trolier-McKinstry

\section{Energy-harvesting materials for smart} fabrics and textiles

Russel Torah, Jake Lawrie-Ashton, Yi Li, Sasikumar Arumugam, Henry A. Sodano, and Steve Beeby

\section{www.mrs.org/bulletin}

www.mrs.org/energy-quarterly

www.mrs.org/mymrs

http://journals.cambridge.org

mrsbulletin-rss

@mrsbulletin

\section{TECHNICAL FEATURE}

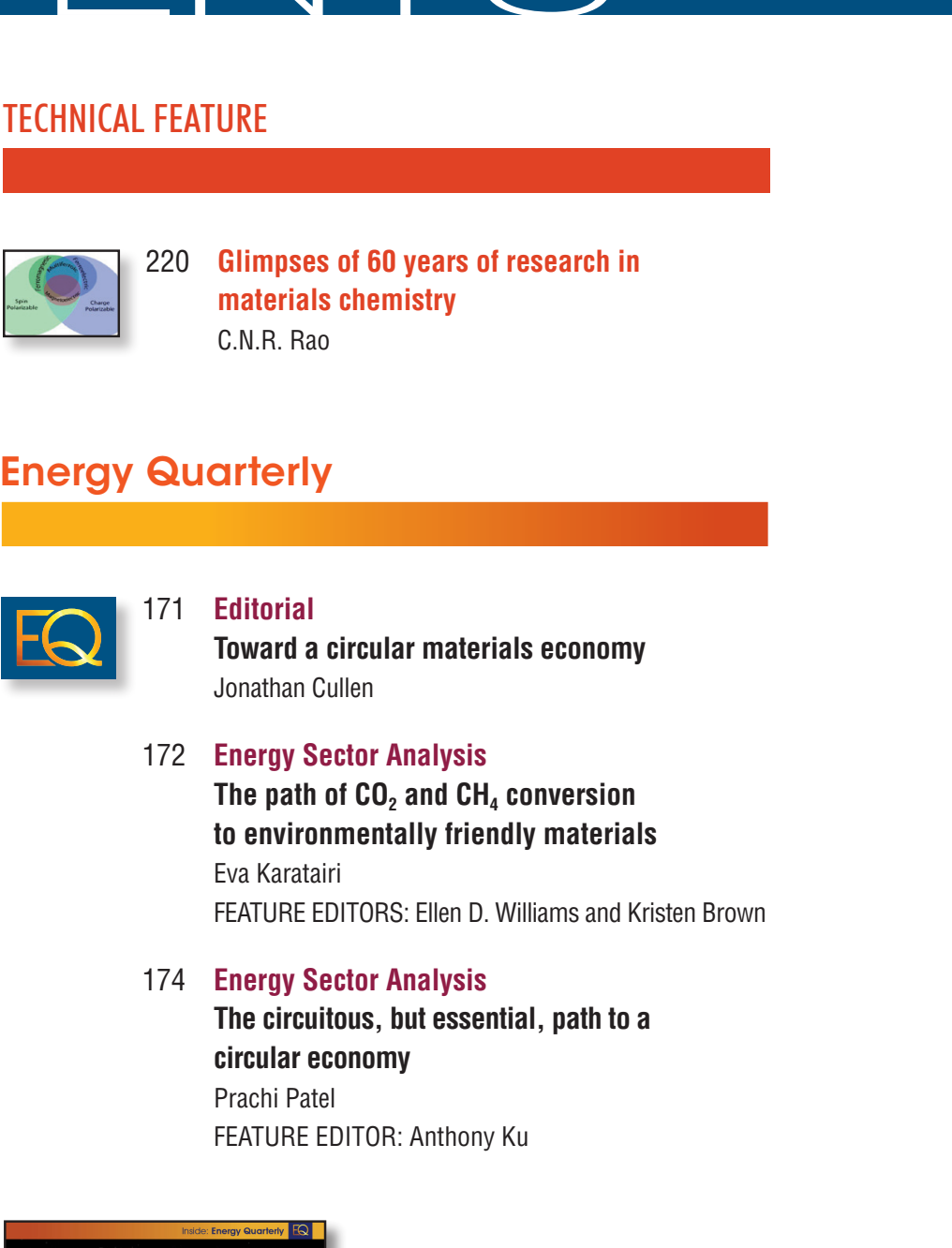

220 Glimpses of 60 years of research in materials chemistry

C.N.R. Rao

\section{Energy Quarterly}

171 Editorial

Toward a circular materials economy Jonathan Cullen

172 Energy Sector Analysis

The path of $\mathrm{CO}_{2}$ and $\mathrm{CH}_{4}$ conversion to environmentally friendly materials

Eva Karatairi

FEATURE EDITORS: Ellen D. Williams and Kristen Brown

174 Energy Sector Analysis

The circuitous, but essential, path to a circular economy

Prachi Patel

FEATURE EDITOR: Anthony Ku 


\section{DEPARTMENTS}

\section{OPINION}

157 Material Matters

Community colleges as gateways to materials science education

Bartlett M. Sheinberg

\section{NEWS \& ANALYSIS}

162 Materials News

- Research Highlights: Perovskites

Prachi Patel

FEATURE EDITOR: Pabitra K. Nayak

- Snapshots of an oxide heterojunction reveal an interfacial atomic shuffle Arthur L. Robinson

- Titanium dioxide metalens controls visible light Lauren Borja

- Origami lattices from flat sheets and patterning yield metamaterials with exotic functions

Prachi Pate

\section{Science Policy}

- US national labs best positioned to advance quantum materials research

William G. Schulz

- EU use of critical raw materials needs improvement for circular economy

- Canada needs to speed up efforts to green its energy and transport sectors

\section{CAREER CENTRAL}

\footnotetext{
ADVERTISERS IN THIS ISSUE

American Elements..

* Goodfellow Corporation

High Voltage Engineering ......................... Inside front cover

* International Centre for Diffraction Data ........................237

* Janis Research Company, LLC .........................................192

* Kurt J. Lesker Company ...................................................169

* Lake Shore Cryotronics, Inc................... Inside back cover

* MilliporeSigma

* Rigaku Corporation ..........................................................226

* J.A. Woollam Co., Inc ............................................. 161

* Please visit us at the exhibit during the 2018 MRS Spring Meeting.
}

\section{SOCIETY NEWS}

227 - Preview: 2018 MRS Spring Meeting \& Exhibit

- Cahill to receive MRS Innovation in Materials Characterization Award

- Mooney to receive Mid-Career Researcher Award for pioneering contributions in biomaterials

- Falk to receive MRS Impact Award for STEM education

- Chueh named 2018 MRS Outstanding Young Investigator for ionic and electronic charge transport

- Wood named 2018 MRS Outstanding Young Investigator for work with transport processes

- Banerjee and Xu to receive MRS Postdoctoral Awards

- Ramesh to present Kavli lecture during 2018 MRS Spring Meeting plenary session

- 2018 MRS Spring Meeting Exhibitors

- Addressing Africa's challenges through materials development

239 Special Insert

- 2017 Materials Research Society Year-End Review

\section{FEATURES}

\section{Book Reviews}

- Thermodynamic Degradation Science: Physics of Failure, Accelerated Testing, Fatigue, and Reliability Applications Alec Feinberg Reviewed by Matthew A. Reilly

- Composite Materials: Concurrent Engineering Approach S.M. Sapuan Reviewed by Adriano Michael Bernardin

- Smart Biomaterial Devices: Polymers in Biomedical Sciences A.K. Bajpai, Jaya Bajpai, Rajesh Kumar Saini, Priyanka Agrawal, and Atul Tiwari Reviewed by Aurelia Meghea

\section{Posterminaries}

Materials shape the Olympic Winter Games Steve Moss 


\section{$\mathrm{M}|\mathrm{R}| \mathrm{S}$}

MATERIALS RESEARCH SOCIETY ${ }^{\oplus}$

Advancing materials. Improving the quality of life.
EDITORIAL OFFICE 506 Keystone Drive, Warrendale, PA 15086-7573 USA Bulletin@mrs.org tel 724.779.2747 fax 724.779.8313 www.mrs.org

\section{About the Materials Research Society}

The Materials Research Society (MRS), a not-for-profit scientific association founded in 1973 and headquartered in Warrendale, Pennsylvania, USA, promotes interdisciplinary materials research. Today, MRS is a growing, vibrant, member-driven organization of over 16,000 materials researchers spanning over 80 countries, from academia, industry, and government, and a recognized leader in the advancement of interdisciplinary materials research.

The Society's interdisciplinary approach differs from that of single-discipline professional societies because it promotes information exchange across many scientific and technical fields touching materials development. MRS conducts three major international annual meetings and also sponsors numerous single-topic scientific meetings. The Society recognizes professional and technical excellence and fosters technical interaction through University Chapters. In the international arena, MRS implements bilateral projects with partner organizations to benefit the worldwide materials community. The Materials Research Society Foundation helps the Society advance its mission by supporting various projects and initiatives.

\section{MRS BOARD OF DIRECTORS}

President Sean J. Hearne, Sandia National Laboratories, USA Immediate Past President Susan Trolier-McKinstry,

The Pennsylvania State University, USA

Vice President and President-Elect Michael R. Fitzsimmons,

Oak Ridge National Laboratory and The University of Tennessee, USA

Secretary Eric A. Stach, University of Pennsylvania, USA

Treasurer David J. Parrillo, The Dow Chemical Company, USA

Executive Director Todd M. Osman, Materials Research Society, USA

Griselda Bonilla, IBM T.J. Watson Research Center, USA

Li-Chyong Chen, National Taiwan University, Taiwan

Matt Copel, IBM T.J. Watson Research Center, USA

Paul S. Drzaic, Apple, Inc., USA

Dawnielle Farrar-Gaines, Johns Hopkins University, USA

Yury Gogotsi, Drexel University, USA

Claudia Gutiérrez-Wing, Instituto Nacional de Investigaciones Nucleares, Mexico

Young-Chang Joo, Seoul National University, South Korea

Lincoln J. Lauhon, Northwestern University, USA

Paul C. McIntyre, Stanford University, USA

Christopher A. Schuh, Massachusetts Institute of Technology, USA

Rachel A. Segalman, University of California, Santa Barbara, USA

Magaly Spector, The University of Texas at Dallas, USA

Molly M. Stevens, Imperial College London, UK

Ehrenfried Zschech, Fraunhofer Institute for Ceramic Technologies and Systems, Germany

\section{MRS OPERATING COMMITTEE CHAIRS}

Academic Affairs Bruce M. Clemens, Stanford University, USA Awards Albert Polman, FOM Institute AMOLF, The Netherlands Government Affairs David P. Norton, University of Florida, USA Meetings Terry Aselage, Sandia National Laboratories, USA Member Engagement Sossina M. Haile, Northwestern University, USA Public Outreach Elizabeth Kupp, The Pennsylvania State University, USA

Publications Shefford P. Baker, Cornell University, USA

\section{MRS HEADQUARTERS}

Todd M. Osman, Executive Director

J. Ardie Dillen, Director of Finance and Administration

Damon Dozier, Director of Government Affairs

Patricia Hastings, Director of Meetings Activities

Eileen M. Kiley, Director of Communications
Editor

Gopal R. Rao, rao@mrs.org

Managing Editor

Lori A. Wilson, Iwilson@mrs.org

News Editor

Judy Meiksin, meiksin@mrs.org

Technical Editor

Lisa C. Oldham, oldham@mrs.org

Editorial Assistants

Michelle S. Raley, raley@mrs.org

Mary Wilmoth

Associate Technical Editor

Carol Tseng

Production/Design

Andrea Pekelnicky-Frye, Rebecca Tokarczyk,

Felicia Turano, and TNQ

Associate Production Editor

Katie Wurtzel

Principal Development Editor

Elizabeth L. Fleischer

Director of Communications

Eileen M. Kiley
Guest Editors

Takao Mori and Shashank Priya

Special Consultant

Angelika Veziridis

Energy Quarterly

Andrea Ambrosini (Chair),

David Cahen, Russell R. Chianelli,

George Crabtree, Elizabeth A. Kócs,

Shirley Meng, Sabrina Sartori,

Anke Weidenkaff, M. Stanley

Whittingham, and Steve M. Yalisove

Advertising/Sponsorship

Mary E. Kaufold, kaufold@mrs.org

Member Subscriptions

Michelle Judt, judt@mrs.org

Non-Member Subscriptions

subscriptions_newyork@cambridge.org
Monika Backhaus, Kristen Brown,

Donna L. Watterson, watterson@mrs.org

\section{EDITORIAL BOARD}

Fiona C. Meldrum (Chair), University of Leeds, UK

Ilke Arslan, Pacific Northwest National Laboratory, USA

V.S. Arunachalam, Center for Study of Science, Technology \& Policy, India

N. (Balu) Balasubramaniam, Bangalore, India (retired)

Christopher J. Bettinger, Carnegie Mellon University, USA

Tommie Kelley, 3M, USA

Igor Lubomirsky, Weizmann Institute, Israe

Amit Misra, University of Michigan, USA

Steven C. Moss, The Aerospace Corporation, USA (retired)

Julie A. Nucci, Cornell University, USA

Linda J. Olafsen, Baylor University, USA

Boaz Pokroy, Technion-Israel Institute of Technology, Israel

Zhiwei Shan, Xi'an Jiaotong University and Hysitron, China

James W. Stasiak, HP Inc., USA

Carol Trager-Cowan, University of Strathclyde, UK

Eric Werwa, Washington, DC, USA

M. Stanley Whittingham, Binghamton University, The State University of New York, USA

Steve M. Yalisove, University of Michigan, USA

\section{VOLUME ORGANIZERS}

2018 Karsten Albe, Technische Universität Darmstadt, Germany Hiroshi Funakubo, Tokyo Institute of Technology, Japan Michael Hickner, The Pennsylvania State University, USA Bethanie Stadler, University of Minnesota, USA

2019 Craig B. Arnold, Princeton University, USA

Claus Daniel, Oak Ridge National Laboratory and The University of Tennessee, Knoxville, USA

Seung Min Han, Korea Advanced Institute of Science and Technology, South Korea Gabriel Montaño, Los Alamos National Laboratory/Northern Arizona University, USA

MRS Bulletin (ISSN: 0883-7694, print; ISSN 1938-1425, online) is published monthly by the Materials Research Society, 506 Keystone Drive, Warrendale, PA 15086-7573. @ 2018 Materials Research Society. Permission required to reproduce content. Periodical postage paid at New York, NY, and at additional mailing offices. POSTMASTER: Send address changes to MRS Bulletin in care of the Journals Department, Cambridge University Press, 100 Brook Hill Drive, West Nyack, NY 10994-2113, USA. Printed in the U.S.A.

Membership in MRS is $\$ 130$ annually for regular members, $\$ 32$ for students, and includes an electronic subscription to MRS Bulletin. Print subscriptions are available to MRS members for an additional $\$ 25$. Individual member subscriptions are for personal use only. Non-member subscription rates are $\$ 560$ (USD) for one calendar year (12 issues). Requests from subscribers for missing journal issues will be honored without charge only if received within six months of the issue's actual date of publication.

MRS Bulletin is included in Current Contents $\otimes /$ Engineering, Computing, and Technology; Current Contents ${ }^{\oplus / P h y s i c a l, ~ C h e m i c a l, ~ a n d ~ E a r t h ~ S c i e n c e s, ~ t h e ~ S c i S e a r c h ~}{ }^{\circledast}$ online database, Research Alert ${ }^{\oplus}$, Science Citation Index $x^{\oplus}$, and the Materials Science Citation Index ${ }^{\top M}$. Back volumes of MRS Bulletin are available on microfiche through University Microfilms Inc., 300 North Zeeb Road, Ann Arbor, MI 48106, USA.

Authors of each technical article appearing in MRS Bulletin are solely responsible for all content in their article(s), including accuracy of the facts, statements, and citing resources. Facts and opinions are solely the personal statements of the respective authors and do not necessarily represent the views of the editors, the Materials Research Society, or Cambridge University Press

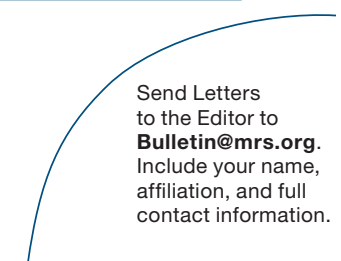

